Note: A modified version of this paper is published in the European Journal of Political Research. Full citation:

MARIEN, S. and WERNER, H. (2018), Fair treatment, fair play? The relationship between fair treatment perceptions, political trust and compliant and cooperative attitudes cross-nationally. European Journal of Political Research. doi:10.1111/1475-6765.12271 (early view)

This research has been generously funded by the Research Foundation Flanders [FWO project grant G075615N]

\title{
Fair Treatment, Fair Play? \\ The Relationship between Fair Treatment Perceptions, Political Trust and Compliant and Cooperative Attitudes Cross-nationally
}

\begin{abstract}
Obtaining citizens' voluntary compliance with political decisions is a fundamental democratic challenge. Fair treatment by public officials plays a key role in theoretical and empirical studies on citizens' compliance and cooperation (e.g. Tyler 2011). Yet it is unclear whether citizens within different societies react to (un)fair treatment in the same way. Using Multilevel Structural Equation Modelling and Multilevel Regression Analysis on the European Social Survey (2010-2; $\mathrm{N}=52,458$ ), we show that perceptions of fair treatment by police officers are associated with higher levels of trust in political institutions and in turn stronger compliant and cooperative attitudes of citizens in 27 countries. Yet the link between perceptions of unfair treatment and institutional trust is stronger in countries in which fair behavior is more prevalent. While fair treatment is often considered to be a universal norm affecting citizens in a uniform way, we shed light on important cross-national variations.
\end{abstract}




\section{INTRODUCTION}

One of the fundamental challenges that any political system faces - how to authoritatively allocate valued goods across society (Easton 1965) - has become even more pertinent in recent years. The declining levels of deference and duty-based citizenship in advanced democracies make it increasingly difficult for these polities to obtain voluntary compliance from their citizens (Nevitte 2014). Yet, voluntary compliance - especially with unfavorable decisions - is a critical resource for democratic systems as coercion is costly and not always normatively desirable (Easton 1965; Marien \& Hooghe 2011). The bulk of political decisions results in winners and losers, therefore, it is clear that this compliance will be difficult to obtain through favorable political outputs alone.

An alternative approach is to study the influence of political procedures - e.g. how political decisions are made or implemented - on compliance (e.g. Ulbig 2002; Esaiasson 2010; Linde 2012; Papadopoulos \& Warin 2007). Law and psychology scholars have argued that citizens will play by the rules if they are treated fairly themselves by the political system (e.g. Tyler 2011; Gibson 1989). The theoretical argument is that fair treatment by authorities increases the willingness to voluntary comply with political decisions because fair treatment enhances the perceived trustworthiness of the political system. Moreover, Tom Tyler recently argued that citizens will not only be more willing to follow political decisions themselves, they will also be more inclined to cooperate with political actors and institutions to sanction citizens who do not abide by these decisions (Tyler 2011). 
Fair treatment is generally considered to be a universal norm (e.g. Bøggild \& Petersen 2015; Tyler 1990), thereby, the beneficial effects of fair treatment on citizens' compliant and cooperative attitudes are expected to be similar across countries. Yet few comparative studies meticulously test this assumption. In contrast, the key argument of this paper is that the strength of the norm of fair treatment differs between countries, and the strength of this norm influences how citizens react when they perceive public officials behaving in an unfair manner. In particular, we expect that the stronger the norm of fair treatment is in a society, the stronger the repercussions of a violation of this norm on citizens' attitudes and behavior towards the political system. This argument calls for a comparative investigation of fairness effects in different national contexts. Building on previous work by Tyler (2011) and Linde (2012), this study offers the first cross-national study that investigates the relationships between perceptions of (un)fair treatment, political trust, compliant and cooperative attitudes in 27 different societies.

In particular, the study focuses on perceptions of fair treatment by public officials at the output side of the political system (i.e. police officers). Two key reasons underlie this choice. First, the nature of fair treatment is more clear on the output side compared to the input side of the political system. Within normative theory there is a clear consensus on the need and nature of the fair implementation of political decisions (e.g. respectful and impartial behavior). Politicians, on the other hand, behave partisan. Therefore, it is less clear-cut what includes fair and unfair behavior of e.g. Members of Parliament (Rothstein \& Stolle 2008; Grönlund \& Setälä 2012). Second, firsthand experience with output institutions, for instance police officers, are more likely among all groups in society than first-hand experience with input institutions (Rothstein \& Stolle 2008). 
By means of Multilevel Structural Equation Modelling techniques using the 2010-2011 European Social Survey, we first investigate how perceived treatment by police officers affects compliant and cooperative attitudes among citizens in 27 countries. Second, we study the influence of societal norms on these relationships. We find that perceptions of fair police treatment are related to higher levels of trust in political institutions, which in turn are related to stronger compliant and cooperative attitudes among citizens. As we theorized, the magnitude of the relation between fair treatment perceptions and trust in political institutions strongly differs between the 27 countries under study. The stronger the societal norm of fair treatment in a country, the stronger the implications of a violation of this norm. Before presenting the data, methods and results of this study, we provide a brief overview of the literature and our theoretical framework. We conclude by summarizing the key findings and how these findings could inspire a number of novel research lines.

\section{WHY FAIR TREATMENT PERCEPTIONS MATTER}

Public acceptance of, and citizens' voluntary compliance with, political decisions are crucial resources for any political system (Easton 1965; Anderson et al. 2005). Today the bulk of the research on compliance takes an instrumental perspective, focusing on rational calculations of costs and benefits, and avoidance based on fear of punishment (Hough et al. 2013). However, this instrumental framework fails to provide a sufficient explanation for voluntary compliance because if it holds, the functioning of a democratic system would be based on control, surveillance and fear resulting in a system of "constant peril of disequilibrium and instability" ( Saphire 1978, p.189; Tyler 1990). Moreover, from the perspective of the individual, compliance 
is not rational as e.g. paying taxes does not pay off because the likelihood of being caught is relatively small compared to the financial gain (Feld \& Frey 2002). Consequently, a key puzzle in political science includes: how can a democratic system foster public acceptance of, and voluntary compliance with, political decisions without being authoritative? How can we solve the social dilemma that it is most beneficial for a society if all people comply yet most beneficial for the individual to not comply?

Law and psychology scholar Tom Tyler $(1990 ; 2011)$ argues that fair treatment is the key to solve this research puzzle. How an authority treats its citizens can offer citizens a signal of its trustworthiness. If citizens perceive they are being treated fairly by public officials, they will believe the political system in general is trustworthy leading them to be more willing to comply with political decisions (De Cremer \& Tyler 2007; see also Jackson \& Sunshine 2007). Moreover, perceptions of fair treatment will not only foster voluntary compliance, according to Tyler (2011) citizens' cooperation with political institutions will also be enhanced. This includes another critical resource for any democratic system as governing a society is easier if a political system can rely on their citizens' cooperation with e.g. the police or courts. Studying fair treatment has become especially relevant in the context of recent societal transformations, such as increasing levels of education and self-expressive values and declining importance of duty-based citizenship conceptions (Dalton \& Welzel 2014). These transformations have been theorized to increase the importance citizens attach to fair governance such as fair treatment by public officials. In times when political systems are increasingly challenged by an assertive citizenry, fair treatment could allow them to gather public compliance with political decisions (Dalton \& Welzel 2014; Carman 2010; Grimes 2006). 
Key elements of fair treatment include respectful behavior, impartiality in the exercise of public power and the justification of decisions by public officials (Leventhal 1980; Mungiu-Pippidi 2006). Fair treatment entails that government officials do not take into consideration anything else about the citizen or the case than is beforehand stipulated in the policy or the law. All people are treated alike irrespective of personal preferences or personal relationships. This rules out the misuse of public power for private benefit, patronage, nepotism, political favoritism, discrimination and other forms of particularistic treatment (Rothstein \& Teorell 2008). In this study, we specifically focus on perceptions rather than actual treatment because previous studies repeatedly found that objective indicators are of less importance if they are not perceived by citizens (e.g. van der Meer and Hakhverdian in press; Esaiasson 2010).

Observing authorities operating fairly can foster political trust for several reasons. This observation can signal that the authorities are interested in the wellbeing of the collective rather than their self-interest, and the members of the collective are valued (Tyler \& Lind 1992). Moreover, this observation can also reveal to citizens that fair procedures are used to make decisions. As Grimes states, "the practices of institutions of authority, in fact are the only relevant expression of that institutions' procedures" (Grimes 2008, p. 527). This can assure citizens that they will not be disadvantaged in the long run. In effect, trust signifies an expectation about future non-malicious and competent behavior of the political system based on an evaluation of its functioning in the past (Baier 1986; Miller \& Listhaug 1990). Based on how citizens are treated, they make an inference about something unobserved (i.e. future behavior of the political system). Uncertainty about the future behavior of the political system is a key characteristic of any trust relation and betrayal and defection are possible outcomes (Gambetta 1988; Luhmann 1968). In sum, how citizens perceive treatment by public officials will shape their evaluation of the 
trustworthiness of political institutions on which predictions about future behavior of the political system are based (i.e. their level of political trust).

A political system that is perceived as trustworthy is in turn rewarded by deference and engagement of its citizens. The more trustworthy a political system is perceived, the higher the likelihood that citizens are to follow the decisions of this trustworthy political system and cooperate with its actors and institutions. The idea that political trust fosters decision acceptance and compliance is a core idea in several seminal theoretical frameworks (Easton 1965; Gamson 1968; Braithwaite \& Levi 2003). David Easton (1965, p. 273) for instance argues in his framework for political analysis that support for the political system is a "reservoir of favorable attitudes or good will that helps members to accept or tolerate outputs to which they are opposed or the effect of which they see as damaging to their wants." Without support for the political system, individuals will refuse to follow unfavorable regulations and follow their self-interest to exploit the system to their advantage. Likewise, Gamson (1967, p. 31) also pointed out that "a wide variety of unpleasant commitments may be accepted with good grace when there is a surplus of political trust". Despite these strong theoretical frameworks, only few scholars have put these arguments to empirical scrutiny (e.g. Hetherington 2005; Marien \& Hooghe 2011; Norris 2011).

The goal of this study is twofold. The first aim of this paper is to shed light on the relation between perceptions of fair treatment, political trust and compliant and cooperative attitudes within a large set of countries. To date, this kind of large scale comparative study is missing which inevitably limits the level of generalizability. The second aim is to offer a theoretical argument supported by empirical evidence on cross-national differences in these relations. 
Because comparative studies are scarce and fair treatment is generally considered to be a universal norm, little attention is paid to potential cross-national variations in fairness effects. In effect, one of the underlying assumptions in these literatures is that people value fairness and consider fair treatment as a norm that should be upheld. In this paper, we want to make the argument that fair treatment is indeed a universal norm but that the strength of this norm varies across societies. We argue that the ensuing differences in citizens' normative expectations regarding fair treatment will influence the effects of perceiving (un)fair treatment.

Given that citizens derive important information about the norms in a society from their observation of actual behavior that surrounds them (Tankard \& Paluck 2016), the overall context of fairness will shape citizens' perceptions of the societal norm regarding fair treatment. In a country in which unfair political treatment is common (e.g. high corruption levels), citizens will assume unfair treatment is the norm and develop corresponding expectations towards the operation of a political system in a country. These expectations in turn are used by citizens to form their trust evaluations and guide their behavior. Political institutions are not evaluated based on an absolute norm but rather in regards to the extent to which they fulfil the normative expectations of the citizenry (Miller \& Listhaug 1990; Norris, 2011; Hooghe, Marien, Oser, 2017). Empirical observations of declining levels of political trust despite increases in democratic quality indeed suggest that expectations play a crucial role in the development of political trust.

The normative expectations of how institutions should act vary between countries based upon the norms within a society (Grönlund \& Setälä 2012; Marien et al. 2015). Citizens living within a fair context will have higher normative expectations regarding the fair treatment by public officials (Linde 2012). We expect that if these normative expectations are violated, for instance because 
one perceives the police acts unfairly, the impact of this violation and expectation disconfirmation on citizens' trust will be comparatively strong (Mutz \& Reeves 2005). In contrast, if citizens for example perceive unfair treatment by the police in a country in which unfair treatment is more common (e.g. higher level of corruption), the normative expectations was much weaker to begin with and accordingly the disappointment smaller. We could also wonder whether it makes sense for individuals to evaluate authorities based on fair treatment if fairness is not a commonly upheld value in a society? For instance, Fischer and colleagues (2011) argue that in fair contexts, fairness information is essentially more useful than in unfair contexts. To date, the impact of contextual factors on fairness effects has largely been neglected in political science research. However, there are some indications in psychological research that the extent to which perceptions of fair treatment affect trust is indeed not equal across contexts e.g. workplaces across the world (Brockner et al. 2001; Fischer et al. 2011; Tyler et al. 2000).

Drawing on the literature on relative deprivation, an opposing theoretical argument could be made: the prevalence of unfair treatment could strengthen the effect of perceiving unfair treatment on political trust. In particular, relative deprivation theory scholars argue that being excluded from access to fundamental rights and values induces a strong sense of frustration (Van Stekelenburg \& Klandermands 2013). Corruption is quite obviously a violation of the norm of impartiality and thus its prevalence may induce strong reactions in the form of distrust, dissent and lower levels of subjective well-being (Tavits 2008). A desire for fair treatment may be much more salient to citizens who are repeatedly confronted with the violation of fair treatment. As a result of these cross-national differences in the saliency of fair treatment, we would expect stronger effects of perceptions of unfair treatment on political trust in countries in which unfair treatment is prevalent. However, this reasoning is not supported by existing empirical studies. For 
instance, procedural information was found to be less important for individuals in hierarchical societies (Tyler et al. 2000). Previous research also suggests that fair treatment is valued more in contexts in which systematic corruption is absent (Linde 2012). For instance, the degree to which individuals reject bribes as morally wrong is lower in countries with higher levels of corruption (Grönlund \& Setälä 2012).

Therefore, in this study, we argue that the effect of fair treatment perceptions on political trust is stronger in contexts in which fair treatment is more widespread. In particular, we argue that the relation between fairness perceptions and political trust depends on the level of corruption in a country. We expect that the societal norm of fair treatment varies between countries as the observation of (un)fair behavior by public officials (e.g. corruption) shapes this societal norm. In countries in which corruption levels are lower, and the societal norm of fair treatment is likely to be stronger, a violation of this norm will have stronger negative effects on political trust than in countries in which the societal norm of fair treatment is weaker as unfair treatment such as corruption is more widespread.

We focus on perceptions of fair treatment by public officials that implement and maintain compliance with political decisions. The focus on institutions at the output side of the political system has the advantage that the role of ideology in citizens' evaluation of fairness is diminished. The focus is not on evaluating processes that might include power struggles between political parties, but on whether political decisions are implemented in a neutral manner (Rothstein \& Eek 2009). In this regard, Linde (2012, p. 513) even states that “'impartiality’ and 'fairness' are first and foremost output-related phenomena". Moreover, institutions at the output side of the political system such as the courts or the police are more a part of the daily life of 
ordinary citizens than institutions at the input side such as parliament. Therefore, their behavior is much more visible to the average individual than that of, for instance, politicians in parliament. Experiences with such street level bureaucrats serve as indicators of the prevalent culture of fairness within a system as Bo Rothstein and Dietlind Stolle (2008) most prominently argued. Accordingly, street level bureaucrats' "behaviors function as important signals to citizens about the moral standard of the society in which they live" (Rothstein \& Stolle 2008, p. 246). Therefore, we argue that individuals use evaluations of fair treatment by the police to form trust judgments for political institutions generally (see also van Sluis \& Van de Walle, 2015)

Particularly, in this study we focus on perceptions of fair treatment by the police which is the most "street level" institution. This approach follows Heath and colleagues' (2016) recent call to study unfair treatment in a more focused way by investigating the specific characteristics of the interaction between citizens and one particular actor e.g. the police. Thereby, we use perceptions of the police as an indicator of the role of output institutions more generally. We expect the same results with other output institutions such as the courts or civil servants. Fair police performance could be considered as a most likely case to find effects of fair treatment perceptions on political trust and compliance and cooperation as this institution is more present in daily life (compared to e.g. courts) and has more degrees of freedom in the implementation of decisions (compared to e.g. a lower level bureaucrat in a municipal administration). If we do not find any effects of perceptions of fair treatment by the police, it is rather unlikely perceptions of fair treatment play an important role in shaping political trust. In sum, the following two hypotheses can be derived from this theoretical framework: 
H1: Perceptions of fair treatment by the police are associated with stronger compliant and cooperative attitudes among citizens. This relationship is mediated by political trust.

H2: The relation between an individual's perception of fair police treatment and political trust is stronger in countries with lower levels of corruption compared to countries with higher levels of corruption.

\section{DATA AND METHODS}

Data

We use the 5th wave of the European Social Survey $(2010 ; \mathrm{N}=52,458)$ to study the relationship between perceptions of fair treatment, political trust, compliant and cooperative attitudes crossnationally. The European Social Survey provides high quality information on social and political attitudes of European citizens. This wave specifically contains variables designed to study perceptions of and attitudes towards output institutions such as the police and the courts (Jackson et al. 2011). Data was collected between 2010 and 2011 by means of face-to-face interviews among representative samples of the population of 25 European countries ${ }^{1}$ and Russia and Israel. Response rates varied by country - from 30.2 percent in Germany to 81.4 percent in Bulgaria with a mean response rate of 60.63 percent.

\footnotetext{
${ }^{1}$ These countries are: Belgium, Bulgaria, Switzerland, Cyprus, Czech Republic, Germany, Denmark, Estonia, Spain, Finland, France, Great Britain, Greece, Croatia, Hungary, Ireland, Israel, Lithuania, The Netherlands, Norway, Poland, Portugal, Russia, Sweden, Slovenia, Slovakia, Ukraine.
} 
Methods of analysis

We employ Multilevel Structural Equation Modelling using the software Mplus7 to model mediated relationships between latent concepts on a cross-national level (Muthén \& Muthén 2015). We account for the clustered nature of the data by studying the factorial and structural parts of our model simultaneously. SEMs are specified separately on the between level (i.e. countries) and within level (i.e. individuals), and estimated on the same dataset. Merging multilevel analysis and structural equation modelling is a rather recent method that is increasingly gaining popularity as it "combines the best of both worlds" (Mehta \& Neale 2005). We use MLR (maximum likelihood with robust standard errors) as an estimator which uses full-information maximum likelihood to handle missing data and is standardly used for ML SEMs (Muthén \& Muthén 2015). This estimator is robust to non-normality and can therefore be used for continuous and categorical variables (Muthén \& Muthén 2015). To further investigate whether and how the role of perceptions of fair treatment varies across countries, we apply Multilevel Regression using stata12.

Measures

Fair police treatment perceptions is the core variable of interest. We use four items drawing on the procedural fairness criteria identified by Leventhal (1980): respect, impartial decision making, justification of decisions and bribe-taking. Respondents were asked e.g.: "About how often would you say that the police make fair, impartial decisions in the cases they deal with?" or "How often would you say that the police in [country] take bribes?" The answer options ranged 
from "never" to "always" on an 11-point scale for the bribe item and from "not at all often" to "very often" on a 4-point scale for the other three items. The bribe item was reversed and recoded to match the other scales.

To achieve a more comprehensive picture of the influence of fair treatment perceptions, we model both individual and aggregate perceptions of fair police treatment. We analyze an individual's perception of fair police treatment and study how differences between individuals affect their political trust level. By aggregating these individual perceptions to the country level, we also obtain an assessment of the level of fair police treatment in a country, which allows tapping into overall perceived levels of fair treatment in a country. This has become a standard approach in studies on corruption, and is considered the best possible way to study the fairness of public official's behavior (Heath et al. 2016). A confirmatory factor analysis yields very good model fit for the latent construct fair police treatment perceptions on the individual level $\left(\operatorname{Chi}^{2}(2)=4.219 \mathrm{p}=.121, \mathrm{RMSEA}=.005[.000-.013], \mathrm{CFI}=1.00\right)$, with all estimates complying with the standardly accepted thresholds (i.e. an insignificant $\mathrm{Chi}^{2}$ which rejects the bad fit hypothesis, RMSEA below .06 with the confidence interval range within .05 and .10 , and CFI above .95. See e.g. Kline 2011). Both convergent validity and reliability of the scale are satisfactory with cronbach's alpha of .80 and factor loadings above .7 (except the bribe item which likely results from the difference in question format). At the between level the model also fits well $\left(\mathrm{Chi}^{2}(2)=4.76 \mathrm{p}=.092, \mathrm{CFI}=.98\right)$ and shows good convergent validity (factor loadings above .8 ) and reliability (cronbach's alpha $=.93$ ).

Political trust is operationalized using a standard measure in comparative research i.e. by assessing trust in five core political institutions: the parliament, political parties, politicians, the 
legal system and the police. Extensive testing of this scale in cross-cultural contexts yielded meaningful measurement models (Marien 2011). The items were phrased: "please tell me on a score of 0 to 10 how much you personally trust each of the institutions I read out. 0 means you do not trust an institution at all, and 10 means you have complete trust”. Political institutions play an important role in shaping a democratic society, hence, we can assume that trust in these institutions is related to a more general evaluation of the political system. The literature suggests either specifying a one-factorial solution with error correlations between the legal system and the police or the mathematically equivalent second order solution with a higher order factor institutional trust, comprising of the two sub-factors output institutions and legislating institutions (Marien \& Hooghe 2011; Rothstein \& Stolle 2008). Here, we chose to model the second-order structure with sub-factors trust in output and legislating institutions. The measurement model fits the data well as the good model fit indices suggest $\left(\mathrm{Chi}^{2}(3)=129.75, \mathrm{p}<001\right.$, RMSEA $=.029$ [.025-.034], CFI =.99). $\mathrm{Chi}^{2}$ is significant, yet this estimate is highly sensitive to sample size making the p-value unreliable for large datasets such as the ESS (Kline 2011). Factor loadings (above .75) and cronbach's alpha (.89) indicate good convergent validity and reliability.

Compliant attitudes are measured using a scale of the acceptance of illegal acts. Law-breaking behavior is difficult to measure due to the social pressure to give desirable answers. Even when they are assured anonymity, respondents will not easily report law-breaking behavior in a survey. In this survey, 97.8 percent of the respondents said they had never made a false insurance claim and 94.4 percent never bought something they thought might be stolen, while it is safe to assume more respondents have engaged in these behaviors. Therefore, in line with previous research, we focus on the acceptability of law-breaking behavior as this indicator is more likely to provide valid results (e.g. Marien 2011; Norris 2011). We measure whether the respondent condones law 
breaking by asking how wrong they thought three kinds of illegal behavior were (i.e. false insurance claim, buy good that one thinks are stolen, commit a traffic offence). Respondents could answer with "not wrong at all”, “a bit wrong”, "wrong” or "seriously wrong”. While social desirability is less problematic with this approach, it is still likely that it will depress variance. As this would lead to an underestimation of the effects, using this measurement provides a conservative test. The model $\mathrm{fit}^{2}\left(\mathrm{Chi}^{2}(8)=1102.45 \mathrm{p}<.001, \mathrm{RMSEA}=.053\right.$ [.05-.06], CFI=.98) and the estimates for convergent validity (above .75 , except traffic offense $=.52$ ) and reliability (cronbach's alpha=.73) are satisfying. While the item on traffic has a lower factor loading, we decided to keep this indicator in the model to tap into a broader variety of illegal acts. The measurement model shows that compliant attitudes are still measured in a satisfactory manner when this item is included.

Cooperative attitudes were also measured with three items addressing the willingness to cooperate with political institutions (i.e. "imagine that you were out and saw someone push a man to the ground and steal his wallet. How likely would you be to call the police?", "How willing would you be to identify the person who had done it?", "how willing would you be to give evidence in court against the accused?"). Respondents could answer "not at all willing", "a bit willing", "somewhat willing" and "very willing". Like the compliant attitudes in this model, the measurement model of cooperative attitudes fits the data well $\left(\mathrm{Chi}^{2}(8)=1102.45, \mathrm{p}<.001\right.$; RMSEA=.053 [.05-.06], CFI=.98) and the estimates for convergent validity (factor loadings above .63) and reliability (cronbach's alpha $=.83$ ) were satisfying.

\footnotetext{
${ }^{2}$ As the construct consists of 3 indicators, the model is just identified and therefore yields perfect fit when tested on its own. Therefore, we test both compliant and cooperative attitudes in the same model with a covariance between the constructs.
} 
To gain insight into the influence of contextual factors, we need a measurement of the level of fair treatment in a country from which citizens can derive the societal norm and subsequently their normative expectations vis-a-vis the political system. We will use the level of corruption as an indicator of the level of objective fair treatment in a country. Corruption is clearly a core violation of the principle of fair treatment by output institutions (Linde 2012). The level of corruption was measured using Transparency International's (2010) Corruption Perceptions Index that is based on estimations of corruption in the public sector by business people, journalists, risk analysts and the general public. Corruption is defined as the abuse of public office for private gain with categories ranging from "country is virtually free from corruption" (10) to "country is almost completely corrupt" (0).

Controls: Outcome perceptions were measured using perceptions of how successful the police are at doing their job (i.e. "how successful police are at preventing crimes?", "how successful police are at catching house burglars?"). Answers ranged from "very successful" to "never successful" on a 10-point scale and were recoded to a 4-point scale to be on the same scale as fair treatment perceptions. On the individual level, model fit $\left(\mathrm{Chi}^{2}(8) 294.868 \mathrm{p}<.001\right.$, RMSEA $=.031[.028-.034]$ and convergent validity (above .74) yielded satisfactory results. In the multilevel regression we control for respondents' age, religiosity and generalized trust as they were found to influence trust in political institutions as well as compliant and cooperative attitudes. We also control for GDP per capita because especially in affluent countries, citizens can afford to have higher normative expectations and pay attention to 'soft' information such as fair treatment because they do not have to worry about basic needs (Inglehart 2008; Dalton \& Welzel 2014). 
An overview of model fit and reliability of all scales can be found in Appendix A .

Analysis

We start by presenting mean averages of the core variables across the 27 countries (Table 1 ). As is common, the variances are larger on the individual level compared to the country level for all variables. Compliant attitudes vary more between individuals than between countries, whereas for trust in political institutions the difference in variances is smaller. Fair police treatment perceptions range from 1.87 in Ukraine to 3.17 in Denmark on a scale from 1 to 4 . As we would expect, we see a geographical pattern with Northern Europeans perceiving the police as more fair compared to inhabitants of Southern and Eastern European countries

\section{[TABLE 1 ABOUT HERE]}

If we compare these aggregate perceptions with other indicators of fair treatment in a country such as corruption level, we see a strong correspondence (Figure 1). A noteworthy difference is the larger variance in corruption levels but both variables have substantial variance and the crossnational patterns displayed are remarkably similar. This indicates that the aggregate fair police treatment perceptions gathered through ESS are on average relatively accurate assessments of the situation in a country.

[FIGURE 1 ABOUT HERE] 
Part 1: Multilevel structural equation model

Subsequently, we specify a structural equation model on two levels to test the first hypothesis that fair police treatment perceptions are associated with higher levels of trust in political institutions which in turn is associated with higher compliant and cooperative attitudes among citizens. We introduce a path from perceptions of fair police treatment on institutional trust on the between level (between countries) and on the within level (between individuals). Institutional trust is specified as a second-order latent construct comprising of two factors (trust in output and trust in legislating institutions). We control for outcome perceptions as another driver of trust on the within and between level. Our model presents a recursive (and therefore identified) path model with a latent measurement structure. A substantial amount of variance in the dependent variables is located at the country level (i.e. intra class correlations higher than 2.0), which emphasizes the need for a multilevel approach (see Appendix B). As multilevel structural equation modelling involves various mediations, we present the results visually in Figure 2 to increase comprehensiveness (an overview of all estimates can be found in Appendix B, Table B1).

\section{Model Fit}

The specified model fits the data well, as all model fit estimates are acceptable according to the generally used thresholds (Figure 2; Kline 2011). However, the overall fit measures could potentially fail to identify misfit on the between level because the much larger sample size of the within level dominates the overall fit. To thoroughly assess the model fit, we apply the partial 
saturated method developed by Ryu and West (2009; see also Ryu 2014) and manually calculate level-specific fit indices. This procedure yields acceptable fit on the within (CFI=.92; $\mathrm{RMSEA}=.03)$ and between level $(\mathrm{CFI}=.97)^{3}$ (More information on this method can be found in Appendix B).

\section{Estimates}

In line with hypothesis 1, the results of the ML SEM show that an individual's perception of fair police treatment is positively related to his/her trust in political institutions (Figure 2). Individuals that perceive that the police treats people fairly have higher levels of trust in both output and legislating institutions. Further, individuals with high levels of institutional trust are less permissive regarding lawbreaking and more willing to cooperate with political institutions. These relationships do not result from outcome perceptions as we control for this. The results show that an individual's perception of outcomes and fair treatment are both significantly related to institutional trust.

The aggregate fair police treatment perceptions are also significantly related to institutional trust: Citizens living in countries in which police treatment is perceived by its citizens as more fair tend to have higher levels of institutional trust (independent of their own perceptions of fair police treatment). This association is very strong, as the standardized coefficient of .90 shows, resulting in an indirect effect on compliant attitudes of .12 and on cooperative attitudes of .21.

\footnotetext{
${ }^{3}$ RMSEA is found to artificially inflate the model fit for models with a low number of degrees of freedom (Kenny, Kaniskan \& McCoach 2014; Ryu \& West 2009). Our between level model comprises of well-fitting measurement models and a just identified path structure. Following the recommendation of Ryu \& West 2009 we can accept the model despite the absence of reliable RMSEA estimates.
} 
Interestingly, aggregate outcome perceptions are not significantly related to institutional trust. Unlike the collective assessment of fair treatment, citizens' collective assessment of police outcome performance in a country does not affect institutional trust. This is in line with previous research that documented objective economic performance did not affect institutional trust, while individual perceptions of economic performance did (van der Meer \& Hakhverdian in press). Interestingly, the collective perception of fair treatment by all citizens in a country as well as an individual's perception of fair police treatment are strongly associated with institutional trust. Even after controlling for perceptions of police outcome performance at the individual and country level, perceived fair police treatment is positively related to institutional trust. In sum, the results of the ML SEM confirm that our conceptual model is a valid representation of the data, as is indicated in the satisfactory model fit. The first hypothesis finds support: both individual and aggregate perceptions of fair police treatment (operationalized by an individual's perception as well as by the assessment of all citizens in a country) are strongly associated with high levels of institutional trust which in turn is associated with higher levels of compliant and cooperative attitudes.

\section{[FIGURE 2 ABOUT HERE]}

Part 2: The moderating role of context: multilevel regression

Turning to the second hypothesis, we investigate whether the effect of an individual's perception of fair police treatment on institutional trust is moderated by the prevalence of unfairness in a country. We study this hypothesis with multilevel regression instead of multilevel SEM because introducing random slopes is too computationally demanding for a SEM with latent factorial structure in the currently available statistical software packages. Moreover, the multilevel 
regression framework provides more opportunities to study variance in slopes and intercepts. As the second hypothesis concerns one specific link in our conceptual model, a regression analysis is adequate as the full model does not need to be tested. ${ }^{4}$

In this analysis, trust in political institutions constitutes the dependent variable and individual perceptions of fair treatment the key independent variable. We control for outcome perceptions, age, religiosity, generalized trust and GDP. We use a standard step-wise approach and estimate several models (Table 2). In a first step, we run a random intercept model to allow the baseline levels of institutional trust to vary between countries. In line with the ML SEM results, an individual's fair treatment perception and outcome perception are both positively related to institutional trust. As expected, we find significant variance between countries in institutional trust. Subsequently, we allow the effect of fair treatment perceptions on trust to vary between countries by estimating a random intercept - random slope model. The Wald-Chi ${ }^{2}$ statistic decreases by almost 50\%, indicating that fixing all slopes to be equal presented a heavy constraint on the model and decreased model fit substantially. The variance of the slope for the effect of perceptions of fair treatment on institutional trust is significant.

\section{[TABLE 2 ABOUT HERE]}

To investigate the difference in slopes in more detail, we look at the deviations from the mean slope per country. Figure 3 shows in which countries fair treatment perceptions are more strongly related to institutional trust, and in which countries fair treatment perceptions matter less

\footnotetext{
${ }^{4}$ Nevertheless, we also test the interaction in Mplus on our conceptual model with manifest variables (mean index). The results are available upon request from the authors. The findings are similar to the findings presented in the multilevel regression.
} 
compared to the overall average (see Appendix B, Table B3 for the corresponding table with standard errors). The relationship between individual-level fair treatment perceptions and institutional trust is strongest in Russia, Norway and Sweden. In contrast, perceptions of fair police treatment appear to matter least in Ukraine, Portugal and Poland. The distribution of countries seems to show a pattern: perceptions of fair police treatment are more strongly associated to institutional trust in Northern European countries than in Southern and Eastern European countries. Russia appears to be an exception to this pattern with a relatively strong relation between fair police treatment perceptions and institutional trust. An in-depth analysis of the Russian case is beyond the scope of the present study. Yet to rule out the possibility of a bias in the results, all analyses are also conducted excluding Russia and yielded substantially the same estimates.

\section{[FIGURE 3 ABOUT HERE]}

Why are perceptions of fair treatment more strongly related to institutional trust in some countries than others? Following hypothesis 2, we argue that the influence of fair police treatment perceptions on citizens' trust evaluations will vary between countries depending on the prevalence of corruption in a country ${ }^{5}$. We predicted that the prevalence of fair treatment by public officials in a country will shape the normative expectations of its citizens, and as a result the influence of perceiving unfair treatment on institutional trust levels. To gain insight into the validity of this theoretical argument we introduce an interaction between individual perceptions of fair police treatment and the country's corruption level (high values mean low levels of corruption). The positive significant interaction effect explains half of the variance of the random

\footnotetext{
${ }^{5}$ It has to be noted that a measure of aggregated fairness perceptions could also be used as a moderating variable. Running the analysis with aggregated fairness perceptions or with corruption yields similar results (see Appendix B).
} 
slope (reduced from .06 to .03; Model III in Table 2). Therefore, the level of corruption in a country explains to a large extent why perceptions of fair treatment are more strongly related to trust in some countries than in others. In particular, in countries with low levels of corruption, an individual's perception of fair police treatment is more important when he/she develops and modifies his/her institutional trust than in countries with a higher degree of corruption. Accordingly, hypothesis 2 is supported by the empirical evidence. This interaction is illustrated in Figure 4.

[FIGURE 4 ABOUT HERE]

Robustness checks

To assess the sensitivity of these analyses, we conduct a number of robustness checks. First, we provide further tests to assess whether perceptions of fair treatment by the police are indeed associated to trust in political institutions as a whole and not simply to trust in the police. We argue that fair treatment by an output institution such as the police signals trustworthiness of political institutions in general and therefore creates a spill-over of trust. Although our conceptual model represents the data well, it is still theoretically possible that fair police treatment is only associated with trust in the police. If we regress trust in legislating institutions (the parliament, political parties and politicians) on perceptions of fair police treatment and control for trust in the police, we still find a positive significant relationship (see Table 3). Accordingly, perceptions of being treated fairly by the police are both directly associated with higher levels of trust in parliament, politicians and political parties as well as indirectly via trust in the police. This is in line with our conceptual model and supports the argument of a spill-over of trust. 


\section{[TABLE 3 ABOUT HERE]}

Second, we investigate potential biases due to influential cases. As was observed in the scatterplots, Russia and Ukraine might disturb the analyses. Based on the multilevel regression models, we estimate Cooks D and DFbeta values. As Russia shows values above the threshold, we run the analyses without this country. Excluding Russia from the analysis does not change the estimates substantially, neither in the ML SEM model nor the Multilevel regression models.

Third, we also examine the possibility of confounds by testing other potential moderators such as GDP and age of democracy. However, none of them performed as well or better than the level of corruption in explaining the variance in slopes between countries.

\section{DISCUSSION}

Why citizens follow political decisions and act cooperatively has preoccupied scholars within a variety of disciplines such as political science, law, economics and psychology (e.g. Tyler 2011; Norris 2011; Dietz et al. 2003). From an instrumental perspective, voluntary compliance has always been irrational but this democratic challenge recently even increased as scholars documented a shift from allegiant to more assertive values among citizens in Western democracies (Dalton \& Welzel 2014). We studied the role of fair treatment by public officials in creating contemporary citizens' consent and cooperation cross-nationally. The results support the argument that citizens use their perception of how they are treated by public officials to assess the 
trustworthiness of the political system. Observing fair treatment by public officials allows citizens to take the risk of trusting the political system, thereby assuming the system will behave non-maliciously and competently in the future. We show that trust in political institutions in turn is related to more compliant and cooperative attitudes.

The empirical test was focused on the behavior of one specific institution i.e. the police. Because of the presence in daily life and the clear normative expectations regarding fair police treatment, we expect that perceptions of fair police treatment relate to how people perceive the trustworthiness of the police as well as the political system as a whole. Our findings indeed indicate that perceiving unfair police treatment is not only associated to lower trust in the police but also to lower levels of trust in other political institutions.

We argue the stronger the societal norm of fair treatment in a society, the stronger a violation of this norm (e.g. perceiving unfair police treatment) will affect political trust. On the other hand, if citizens are confronted with unfair behavior on a daily basis, they are likely to believe this is the societal norm and perceiving unfair police treatment will not affect their trust strongly. In this paper, we show that the strength of the relation between fair treatment perceptions and political trust indeed varies depending on the level of corruption in a country. In countries in which systematic corruption is absent, the relation between fair treatment perceptions and political trust is the strongest. In these type of contexts in which fair treatment is expected, a violation of the fair treatment norm is likely to have a stronger effect on citizens' political trust than in contexts characterized by systematic corruption. 
These findings emphasize the importance of two emerging avenues in comparative political science research. First, they stress the relevance and value of the procedural fairness framework for political science research (Birch 2010; Esaiasson et al. in press). Citizens do not only evaluate a system's functioning based on its outcomes but also on how they are treated by the authorities. Respectful and impartial behavior reveals important information about the trustworthiness of political institutions and is used by citizens as a predictor for their future functioning. Even if we control for citizens' outcome perceptions, fair treatment perceptions exhibit strong and stable associations with trust in political institutions using different operationalizations and statistical models. An individual's perception of fair treatment as well as the collective assessment of the citizenry in a country is positively related to one's political trust.

Interestingly, an individual's perception of the quality of political outcomes affects his/her political trust but not the collective assessment of the citizens in one's country. This finding adds to the emerging empirical evidence that questions the role actual outcome performance plays for judgements of trustworthiness of a political system (van der Meer \& Hakhverdian in press). An individual's perception of the quality of political outcomes is frequently found to strongly affect political trust (e.g. Kestilä-Kekkonen \& Söderlund 2015), but this perception is not necessarily accurate. As a result, citizens' collective assessment of outcome performance might be unrelated to actual outcomes. Objectively assessing outcome performance might be rather difficult for citizens. In contrast, citizens are apparently capable of assessing the level of fair treatment in their country, as the strong correlation between corruption and aggregate fair treatment perceptions as well as the significant effect on the aggregate level reveals. Unfortunately, no reliable comparable data is available to assess the success of the police in a country in preventing and solving crimes in all 27 countries. However, building on the scholarship on political outcomes as a driver of 
political trust, it is safe to assume this objective outcome performance will have little impact on political trust (Mishler \& Rose 2001). In sum, we believe that in addition to studying the effects of political outcomes, studying how political decisions are made and implemented and how this affects citizens' attitudes and behaviors should be high on the research agenda of comparative political scientists.

Second, this study also adds to the emerging empirical evidence on how contextual factors influence the criteria citizens use to develop political trust (e.g. Hakhverdian \& Mayne 2012; Čermák et al. 2016). Neundorf (2010) for instance showed that having lived under socialist rule impacts the drivers of political trust. This study reveals that the relation between fair treatment perceptions and political trust differs strongly across countries, and provides further evidence that the drivers of political trust differ cross-nationally. While empirical studies often strive towards finding the single true composition of trust determinants, the present study suggests that trust depends on different determinants in different contexts. Further research on the conditionality of drivers of trust in different contexts presents another interesting research agenda.

We should note that the choice for a comparative cross-sectional study also results in a number of limitations, especially in our ability to make firm causal statements. For instance, some studies find evidence for a reciprocal relationship between corruption and trust (Wroe et al. 2013; Chang \& Chu 2006), yet, Chang an Chu (2006) conclude that there is still a substantial causal flow running from corruption to trust. We tried to strengthen our research design by not only studying an individual's perception of fair treatment, which might be endogenous to the political trust measure (Van de Walle \& Bouckaert 2003), but to complement this with an aggregated measurement of fair treatment. The significant relationship between the aggregate measurement 
of fair treatment and institutional trust strengthens our theoretical expectation that the observation of fair treatment in the past increases one's trust that institutions will function favorably in the future. The results from experimental studies further corroborate the causal argument we outlined (e.g. Tyler 2011). In addition, our key argument concerns the differences in associations between countries and not the causal flow. Nevertheless, the application of causal methods such as experiments or panel data would allow future studies to investigate the causal mechanisms more in depth. Especially cross-national experiments are warranted. Whereas previous studies assumed fair treatment is a universal norm, this study provided an important qualification to this theoretical claim. The strength of the norm of fair treatment seems to vary across countries affecting the implications of violations of this norm. Important variations in fair treatment perceptions of citizens within 27 countries were uncovered as well as variations in the relation of these perceptions to political trust and compliance. This study showed that the overall fairness context in which citizens operate offers an important explanation for this cross-national variation.

\section{REFERENCES}

Anderson, C.J. et al., 2005. Losers' Consent: Elections and Democratic Legitimacy, Oxford University Press.

Baier, A., 1986. Trust and Antitrust. Ethics, 96(2), pp.231-260.

Bøggild, T. \& Petersen, M.B., 2015. The Evolved Functions of Procedural Fairness : An Adaptation for Politics. In T. K. Shackelford \& R. D. Hansen, eds. The Evolution of Morality. Springer US, pp. 247-276.

Braithwaite, V. \& Levi, M., 2003. Trust and governance, New York: Russel Sage Foundation.

Brockner, J. et al., 2001. Culture and procedural justice: The influence of power distance on reactions to voice. Journal of Experimental Social Psychology, 37(4), pp.300-315.

Carman, C., 2010. The process is the reality: Perceptions of procedural fairness and participatory democracy. Political Studies, 58(4), pp.731-751.

Čermák, D., Mikešová, R. \& Stachová, J., 2016. Regional differences in political trust: 
Comparing the Vysocina and Usti Regions. Communist and Post-Communist Studies, 49(2), pp.137-146.

Chang, E.C.C. \& Chu, Y., 2006. Corruption and Trust: Exceptionalism in Asian Democracies? 68(2), pp.259-271.

De Cremer, D. \& Tyler, T.R., 2007. The effects of trust in authority and procedural fairness on cooperation. The Journal of applied psychology, 92(3), pp.639-649.

Dalton, R.J. \& Welzel, C., 2014. The Civic Culture Revisited. From Allegiant to Assertive Citizens, Cambridge: Cambridge University Press.

Dietz, T., Ostrom, E. \& Stern, P., 2003. The Struggle to Govern the Commons. Science, 302, pp.1907-1912.

Easton, D., 1965. A framework for political analysis, Englewood Cliffs, NJ: Prentice-Hall.

Esaiasson, P., 2010. Will citizens take no for an answer? What government of officials can do to enhance decision acceptance. Political Science Review, 2(3), pp.351-371.

Feld, L.P. \& Frey, B.S., 2002. Trust breeds trust: How taxpayers are treated. Economics of governance, 3(2), pp.87-99.

Fischer, R. et al., 2011. Are Perceptions of Organizational Justice Universal? An Exploration of Measurement Invariance Across Thirteen Cultures. Social Justice Research, 24(4), pp.297313.

Gambetta, D., 1988. Trust : making and breaking cooperative relations, New York: Blackwell.

Gamson, W. a., 1968. Power and Discontent, Homewood: Dorsey.

Gibson, J.L., 1989. Understandings of justice: Institutional legitimacy, procedural justice, and political tolerance. Law and Society Review, 23(3), pp.469-496.

Grimes, M., 2008. Consent, political trust and compliance: Rejoinder to Kaina's remarks on “Organizing consent.” European Journal of Political Research, 47(4), pp.522-535.

Grimes, M., 2006. Organizing consent: The role of procedural fairness in political trust and compliance. European Journal of Political Research, 45(2), pp.285-315.

Grönlund, K. \& Setälä, M., 2012. In Honest Officials We Trust: Institutional Confidence in Europe. The American Review of Public Administration, 42(5), pp.523-542.

Hakhverdian, A. \& Mayne, Q., 2012. Institutional trust, education, and corruption: a micro-macro interactive approach. Journal of Politics, 74(3), pp.739-750.

Hetherington, M.J., 2005. Why trust matters: Declining political trust and the demise of American liberalism, Princeton: Princeton University Press.

Hough, M., Jackson, J. \& Bradford, B., 2013. The drivers of police legitimacy: some European research. Journal of Policing, Intelligence and Counter Terrorism, 8(2), pp.144-165.

Inglehart, R.F., 2008. Changing Values among Western Publics from 1970 to 2006. , 31(March), pp.130-146.

Jackson, J. et al., 2011. Developing European indicators of trust in justice. European Journal of 
Criminology, 8(4), pp.267-285.

Jackson, J. \& Sunshine, J., 2007. Public confidence in policing: A neo-durkheimian perspective. British Journal of Criminology, 47(2), pp.214-233.

Kestilä-Kekkonen, E. \& Söderlund, P., 2015. Is it All about the Economy? Government Fractionalization, Economic Performance and Satisfaction with Democracy across Europe, 2002-13. Government and Opposition, FirstView(1), pp.1-31.

Kline, R., 2011. Principals and Practices of Structural Equation Modelling 3rd ed., New York: Guilford Press.

Leventhal, G.S., 1980. What should be done with equity theory? New approaches to the study of fairness in social relationships. In K. Gergen, M. Greenberg, \& R. Willis, eds. Social exchange: advances in theory and research. New York: Plenum Press, pp. 25-55.

Linde, J., 2012. Why feed the hand that bites you? Perceptions of procedural fairness and system support in post-communist democracies. European Journal of Political Research, 51(3), pp.410-434.

Luhmann, N., 1968. Vertrauen: ein Mechanismus der Reduktion sozialer Komplexität, Stuttgart: F. Enke.

Marien, S., 2011. Measuring political trust across time and space. In M. Hooghe \& S. Zmerli, eds. Political Trust. Why Context Matters. Colchester: ECPR Press, pp. 13-46.

Marien, S. \& Hooghe, M., 2011. Does political trust matter? An empirical investigation into the relation between political trust and support for law compliance. European Journal of Political Research, 50(2), pp.267-291.

Marien, S., Hooghe, M. \& Oser, J., 2015. Great Expectations: The Effect of Democratic Ideals and Evaluations on Political Trust; A Comparative Investigation of the 2012 European Social Survey.

Van der Meer, T. \& Hakhverdian, A., Political trust as the evaluation of process and performance: A cross-national study of forty-two European democracies. Political Studies, in press.

Mehta, P.D. \& Neale, M.C., 2005. People are variables too: multilevel structural equations modeling. Psychological methods, 10(3), pp.259-284.

Miller, A.H. \& Listhaug, O., 1990. Political Parties and Confidence in Government: A Comparison of Norway, Sweden and the United States. British Journal of Political Science, 20(3), p.357.

Mishler, W. \& Rose, R., 2001. What Are the Origins of Political Trust?: Testing Institutional and Cultural Theories in Post-communist Societies. Comparative Political Studies, 34(1), pp.3062.

Mungiu-Pippidi, A., 2006. Corruption: Treatment and Diagnosis. Journal of Democracy, 17(3), pp.86-99.

Muthén, L.K. \& Muthén, B.O., 2015. Mplus User’s Guide 7th ed., Los Angeles, CA: Muthén \& Muthén. 
Mutz, D.C. \& Reeves, B., 2005. The New Videomalaise: Effects of Televised Incivility on Political Trust. The American Political Science Review, 99(1), pp.1-15.

Nevitte, N., 2014. The Decline of Deference Revisited. In R. J. Dalton \& C. Welzel, eds. The Civic Culture Transformed. Cambridge: Cambridge University Press, pp. 35-58.

Norris, P., 2011. Democratic deficit. Critical citizens revisited, Cambridge: Cambridge University Press.

Papadopoulos, Y. \& Warin, P., 2007. Are innovative, participatory and deliberative procedures in policy making democratic and effective? European Journal of Political Research, 46(4), pp.445-472.

Rothstein, B. \& Eek, D., 2009. Political Corruption and Social Trust: An Experimental Approach. Rationality and Society, 21(1), pp.81-112.

Rothstein, B. \& Stolle, D., 2008. The State and Social Capital: An Institutional Theory of Generalized Trust. Comparative Politics, 40(4), pp.441-459.

Rothstein, B. \& Teorell, J., 2008. What is quality of government? A theory of impartial government institutions. Governance: An International Journal of Policy, Administration, and Institutions, 21(2), pp.165-190.

Ryu, E., 2014. Model fit evaluation in multilevel structural equation models. Frontiers in Psychology, 5(FEB), pp.1-9.

Ryu, E. \& West, S.G., 2009. Level-specific evaluation of model fit in multilevel structural equation modeling. Structural Equation Modeling, 16(4), pp.583-601.

Saphire, R.B., 1978. Specifying Due Process Values: Toward a More Responsive Approach to Procedural Protection. University of Pennsylvania Law Review, 127(1), pp.111-195.

van Sluis, A. \& Van de Walle, S., 2015. The significance of police-citizen contacts for public trust in the police in the Netherlands. European Journal of Policing Studies, 3(1), pp.78-98.

Van Stekelenburg, J. \& Klandermands, B., 2013. The Social Psychology of Protest. Current Sociology, 61(5), pp.886-905.

Tankard, M.E. \& Paluck, E.L., 2016. Norm perceptions as a vehicle for social change. Social Issues and Policy Review, 10(1), pp.181-211.

Tavits, M., 2008. Representation, Corruption, and Subjective Well-Being. Comparative Political Studies, 41(12), pp.1607-1630.

Transparency International, 2010. Corruption Perception Index 2010. Available at: http://www.transparency.org/cpi2010/results [Accessed July 31, 2016].

Tyler, T.R., 2011. Why people cooperate: The Role of Social Motivations, Princeton: University Press.

Tyler, T.R., 1990. Why people obey the law, Princeton: University Press.

Tyler, T.R. \& Lind, E.A., 1992. A relational method of authority in groups. Advances in Experimental Social Psychology, 25, pp.115-191. 
Tyler, T.R., Lind, E.A. \& Huo, Y.J., 2000. Cultural values and authority relations: The psychology of conflict resolution across cultures. Psychology, Public Policy, and Law, 6(4), pp.1138-1163.

Ulbig, S.G., 2002. Policies, Procedures, and People: Sources of Support for Government? Social Science Quarterly, 83(3), pp.789-809.

Van de Walle, S. \& Bouckaert, G., 2003. Public Service Performance and Trust in Government: The Problem of Causality. International Journal of Public Administration, 26(8), pp.891913.

Wroe, A., Allen, N. \& Birch, S., 2013. The role of political trust in conditioning perceptions of corruption. European Political Science Review, 52(May 2012), pp.175-195. 